Revue bibliographique pour le domaine irano-aryen

\title{
Valeska Hartmann. "Der Traum von der Fremde. Persische Vorstellungswelten im Bühnenbild der opera seria des achtzehnten und neunzehnten Jahrhunderts"
}

Reinhardt Pirngruber

\section{(2) OpenEdition}

\section{Journals}

Electronic version

URL: https://journals.openedition.org/abstractairanica/53462

DOI: 10.4000/abstractairanica.53462

ISSN: 1961-960X

Publisher:

CNRS (UMR 7528 Mondes iraniens et indiens), Éditions de l'IFRI

Electronic reference

Reinhardt Pirngruber, "Valeska Hartmann. "Der Traum von der Fremde. Persische Vorstellungswelten im Bühnenbild der opera seria des achtzehnten und neunzehnten Jahrhunderts"', Abstracta Iranica [Online], Volume 42-43 | 2021, document 55, Online since 30 December 2021, connection on 01 January 2023. URL: http://journals.openedition.org/abstractairanica/53462 ; DOI: https://doi.org/ 10.4000/abstractairanica.53462

This text was automatically generated on 1 January 2023.

All rights reserved 


\title{
Valeska Hartmann. "Der Traum von der Fremde. Persische Vorstellungswelten im Bühnenbild der opera seria des achtzehnten und neunzehnten Jahrhunderts"
}

\author{
Reinhardt Pirngruber
}

\section{REFERENCES}

Valeska Hartmann. "Der Traum von der Fremde. Persische Vorstellungswelten im Bühnenbild der opera seria des achtzehnten und neunzehnten Jahrhunderts" in R. Rollinger, K. Ruffing, L. Thomas (eds.). Das Weltreich der Perser. Rezeption - Aneignung Verargumentierung. Wiesbaden: Harrassowitz Verlag, 2019, p. 107-140.

V. Hartmann traces the development of stage designs for operas whose protagonists were hero(ines) from Near Eastern antiquity, with Persian kings occupying pride of place, from Baroque to Historicism. She demonstrates a gradual increase in the use of elements considered genuinely Achaemenid, e.g. bull capitals, culminating in the use of drawings made during the excavations of Bottà and Layard as archetypes. 


\section{AUTHORS}

\section{REINHARDT PIRNGRUBER}

Institut für Orientalistik, Wien 